\title{
DETERMINATION OF OPTIMUM OF CAPITAL-LABOUR RATIO WITHIN TWO-FACTOR PRODUCTION FUNCTIONS WITH NON-ZERO SUBSTITUTION BY THE PRINCIPLE OF EQUAL MARGIN
}

\author{
Oleksandr Yankovyi ${ }^{1}$ \\ Odessa National Economic University, Ukraine \\ Lydmila Sotnychenko² \\ National University "Odessa Maritime Academy", Ukraine \\ Angelina Petrashevska ${ }^{3}$ \\ O.S. Popov Odessa National Academy of Telecommunications, Ukraine
}

\begin{abstract}
Theoretical and applying aspects of using the principle of equal margin in microeconomics for the determination of the optimal capital-labour ratio within two-factor production functions with non-zero substitution are discussed. The use of the proposed algorithm is carried out on the example of such production functions as Cobb-Douglas function, linear, Leontief function, which are generalized by a function with constant elasticity of the substitution of factors. The purpose of this article is to offer a fairly simple opportunity for the economicmathematical determination of optimal capital-labour ratio within two-factor production functions with the non-zero substitution of resources on the basis of the principle of equal margin. Justified the principle of equal margin for the determination of optimal capital-labour ratio within two-factor production functions with nonzero substitution. The results of the study show that there are possibilities of the proposed approach to the analysis of extreme interconnections between production and aggregate factors of production. Practical recommendations on the application of these production functions in the process of econometric modelling and forecasting are given.
\end{abstract}

Key words: principle of equal margin, production function, substitution of factors, optimal capital-labour ratio.

JEL Classification: C61, C65, D20, D24

\section{Introduction}

The main purpose of the enterprise in modern economic science and practice is the maximization of profit. However, different enterprises can set different goals, which depend on the interests of their economic agents: owners of enterprises, managers, shareholders, etc. For example, managers of large enterprises may care, first of all, about strengthening their own position. They may have goals to increase production (works, services) or increase the value of the enterprise because the owners of the enterprises will judge about the effectiveness of managers' activities based on these indicators. The main goal of the company in the wellknown Japanese model is the growth of added value.

At the present time, world economic thought has developed various theories of optimization of the enterprise. In these models, the maximization of the efficiency of management activity, the prestige of the enterprise, the conquest and maintenance of a certain market share, the development of new markets, etc., is put forward to maximizing profits. Thus, in microeconomics, there is a well-known approach to the optimization of the enterprise in the case of two aggregated production factors: fixed assets $(K)$ and labour $(L)$. The essence of this approach is to determine a point with coordinates $K_{1}$, $L_{1}$, which maximizes output $Y_{1}$ with given general capital costs $C_{1}=K_{1}+L_{1}$ (minimizes overall costs $C_{1}$ for a certain output $Y_{1}$ ). The main approach to the solution of this problem is the apparatus of production functions (PF), in particular, their geometric interpretation in the form of isoquants, isocosts, and the like. Thus, it is possible to specify at least four two-factor PFs that are most popular

\footnotetext{
Corresponding author:

${ }^{1}$ Department of Economics of Enterprise and Entrepreneurship, Odessa National Economic University.

E-mail: yankovoy@ukr.net

${ }^{2}$ Department of Sea Transport Economics and Management, National University “Odessa Maritime Academy”.

E-mail: terra.scor@yandex.ua

${ }^{3}$ Department of Economics of Enterprise and Corporate Management, O.S. Popov Odessa National Academy of Telecommunications.

E-mail: pangelina@i.ua
} 
in economic of resources or the CES-function; 2) CobbDouglas PF; 3) linear PF; 4) Leontief function. This raises the following problem: how to determine the optimal combination of production factors in each specific case of the adequate application of a certain PF among the above four functions.

\section{Analysis of recent research and publications}

Some aspects of the considered problem are found in (Pindyke et al., 2002; Halperin, 2004; Perloff, 2014) among the authors, who have recently been using the PF, generalized by the CES-function.

For example, (Debertin, 2012) considers the algebraic conditions for maximizing neoclassical PFs based on the analysis of the signs of the first and second derivatives of additive and multiplicative models of agricultural production. He also gives a geometric interpretation of the presence of local extrema and a global maximum based on the saddle points of the surface of the PF. At the same time, Debertin does not link the problem of maximizing output with the determination of the level of the optimal capital-labour ratio in the studied PF.

It is necessary to note the works of (Borovsky, 2008; Kazakova, 2013; Podladchikov, 2012; Cherevko, 2007; Shumska, 2007) publications. However, there is no systematic approach to the solution of the discussed problem in the modern economic literature.

So far, there has not been a comprehensive study of existing approaches to the determination of optimal capital-labour ratio $K_{1} / L_{1}$ for any $\mathrm{PF}$, in particular, for econometric models, generalized by the CES-function. It means that there are a general understanding and geometric interpretation of this problem, but there is no universal methodological tool for its solution.

\section{Setting targets}

The purpose of the paper is to offer a fairly simple opportunity for the economic-mathematical determination of optimal capital-labour ratio $K_{1} / L_{1}$ within two-factor PF with the non-zero substitution of resources on the basis of the principle of equal margin, which is well-known in the microeconomics.

\section{Formulation of the problem in graphical form}

The graphic definition of the optimum of the capitallabour ratio of the enterprise is as follows. Effective ways of obtaining a given volume of output are determined by the corresponding isoquant of PF or the map of isoquants, which represents the multiplicity of the choice of output volumes if it is possible. The economic opportunities of the enterprise are set by isocost of PF or the map of isocosts, which is the variation of the budget allocated for the obtaining of production factors if it is possible. The optimal combination of resources is graphically depicted in Fig. 1, which shows the isoquants and isocosts of the neoclassical PF.

Combinations of production factors $K$ and $L$, marked by the points $A, B, F$, lie on the isocost $C_{1}$ and on two isoquants $Y_{1}, Y_{2}$ in Fig. 1. But the best of them is a combination at point $B$ because it provides the largest output of products $Y_{2}$. Consequently, a combination of production factors that maximizes output is the point of touch of isocost and the highest of possible isoquants.

Combinations of factors $K$ and $L$, marked with points $D$, $B, E$ in Fig. 1, lie on one isoquant and on two isocosts $C_{1}$, $\mathrm{C}_{2}$. All of them are effective, but the best from an economic point of view is a combination at point $B$ because it needs the smallest amount of cost $C_{1}$. Consequently,

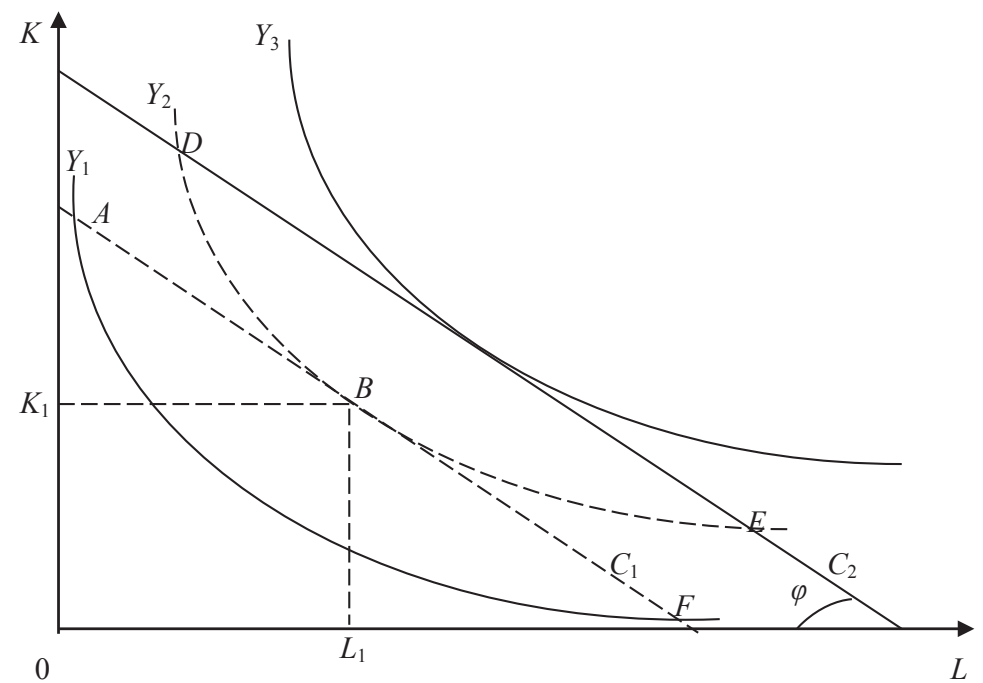

Figure 1. Determination of the optimal point on the map of isoquants and isocosts of the neoclassical PF $\left(Y_{3}>Y_{2}>Y_{1} ; C_{2}>C_{1}\right)$

Source: built by the authors 
a combination of production factors minimizing costs is the point of contact of isoquant to the lowest possible isocost.

Thus, in Figure 1 at point $B$ with the coordinates $K_{1}, L_{1}$, there is an optimal capital-labour ratio of the enterprise, which ensures the maximization of output at given total costs (minimization of the total costs for the given production output).

\section{The microeconomic principle of equal margin}

We propose a fairly simple possibility of econometricmathematical determination of optimal capital-labour ratio $K_{1} / L_{1}$ within two-factor PFs based on the principle of equal margin, which is known in the microeconomics. Let us briefly consider its essence.

Let the production resources be to some extent interchangeable, which means that a certain volume of one production factor can be compensated by the corresponding volume of another. This property is called the hypothesis of the interchangeability of factors, or the assumption of their non-zero substitution. In other words, for the two-factor PF $Y=f(K, L)$ is performed equality

$$
f(K+\Delta K, L)=f(K, L+\Delta L) \neq 0 \text {. }
$$

Mathematically, this means that the marginal products of capital $M P_{K}$ and labour $M P_{L}$ within this $\mathrm{PF}$ are different from zero, and the marginal rate of replacement of production factors of $M R S_{L K}$ exists in the form of a certain real number.

From the course of geometry, it is known, that if the line is tangent to some curve, then at the point of contact the angles of inclination of these lines coincide. The inclination of the isoquant is the marginal rate of replacement of production factors $M R S_{K L}$, which depends on the specifics of the production process at the enterprise. It is determined by the ratio of the marginal products of capital $M P_{K}$ and labour $M P_{L}$ :

$$
-\frac{\Delta K}{\Delta L}=M R S_{L K}=-\frac{M P_{K}}{M P_{\mathrm{L}}} .
$$

The minus sign in formula (2) indicates that one production factor increases, while another decreases with a fixed volume of output.

The inclination of isocost is a market rate of replacement of production factors, equal to the ratio of their prices $p_{K}, p_{L}$ :

$$
-\frac{\Delta K}{\Delta L}=\operatorname{tg} \phi=-\frac{p_{K}}{p_{\mathrm{L}}},
$$

where $\varphi$ is the angle of inclination of the isocost to the abscissa $0 L$ in Fig. 1

It is clear that at the point of the optimal combination of production factors, the inclination of isoquant and isocost coincide, that is, the equality is fulfilled

$$
M R S_{L K}=-\frac{p_{K}}{p_{\mathrm{L}}} .
$$

Hence, two equivalent conditions characterizing the optimum of the enterprise as a commodity producer are deduced in the microeconomics.
Condition 1. The ratio of marginal products of production factors is equal to the ratio of their prices:

$$
\frac{M P_{K}}{M P_{L}}=\frac{p_{K}}{p_{\mathrm{L}}} .
$$

Condition 2. Marginal products of production factors belong to 1 monetary unit must be the same:

$$
\frac{M P_{K}}{p_{K}}=\frac{M P_{L}}{p_{\mathrm{L}}} \text {. }
$$

The second condition is often called thel principle of equal margin, which implies that the price-weighted products of the factors of production must be aligned. Realizing these conditions, an enterprise achieves the condition of inner balance, that is, the best combination of resources.

Obviously, in the case of measuring all variables $Y, K, L$ in monetary units, the marginal products of production factors are also in value terms. Therefore, formula (6) can be represented as follows:

$M P \Delta_{K}=M P \Delta_{L}$,

where $M P^{*}{ }_{K}, M P^{*}$ are marginal products of capital and labour, expressed in terms of their value in a natural dimension.

Consequently, the essence of the principle of equal margin is the equality of the marginal products of production factors in conditions of thre optimal capitallabour ratio of the enterprise.

For example, if $p_{K}$ is the price of one machine-hour of the work of the technological equipment in UAH and $p_{L}$ is the tariff of one man-hour of labour in UAH, then for the enterprise at point $B$ in Fig. 1 the following interrelation is performed. The marginal product of assets, expressed in terms of machine-hours of operation of technological equipment, is equal to the marginal product of labour, expressed in terms of man-hours of work of production personnel.

\section{The mathematical derivation of formulas for the optimal capital-labour ratio for PFs, generalized by CES-function}

From formula (7) it follows that at the point of the optimal capital-labour ratio at the enterprise the marginal rate of replacement of production factors becomes the form

$$
M R S_{L K}=\frac{M P *_{K}}{M P *_{\mathrm{L}}}=1,
$$

that is equal to one.

It is easy to prove the validity and the inverse statement. If the condition (8) is fulfilled for the marginal norm of substitution of production factors, then the enterprise as a commodity producer is at the point of optimal capital-labour ratio.

Taking into account the obtained theoretical results, we come to the following conclusion. It is enough to find the expression of margin norm of substitution of resources and equate it to one for any two-factor 
production function with the non-zero substitution of production factors using the principle of equal margin to determine the coordinates of the optimal capitallabour ratio. It is assumed that the marginal products of the production factors are expressed in natural units.

In general terms, this rule is formulated by follows. The principle of equal margin to determine the optimal capital-labour ratio of any two-factor production function with non-zero substitution is to fulfil the condition

$$
M R S_{L K}=\frac{\partial Y}{\partial K}: \frac{\partial Y}{\partial L}=\frac{f_{K}^{\prime}(K, L)}{f_{L}^{\prime}(K, L)}=1 .
$$

From formula (9), the determination of optimal capital-labour ratio $K_{1} / L_{1}$ is quite simple. Let us illustrate this by the example of the most popular in economic research Cobb-Douglas PF:

$$
Y=A K^{\alpha} L^{\beta},
$$

where $A$ - coefficient of the scale $(0<A)$; $\alpha, \beta-$ parameters that determine elasticity of product output by individual factors $(0<a<1,0<\beta<1)$.

PF (10) relates to neoclassical functions (see Fig. 1) when performing restrictions on unknown parameters specified in brackets. Its elasticity of the substitution of the factors $\sigma_{K L}$ is constant and is equal to one.

The first partial derivatives of the Cobb-Douglas PF expressed on $K$ and $L$ are:

$$
\frac{\partial Y}{\partial K}=A \alpha K^{\alpha-1} L^{\beta} ; \frac{\partial Y}{\partial L}=A \beta K^{\alpha} L^{\beta-1} .
$$

For PF (10), we write the condition (9):

$$
M R S_{L K}=\frac{\partial Y}{\partial K}: \frac{\partial Y}{\partial L}=\frac{A \alpha K^{\alpha-1} L^{\beta}}{A \beta K^{\alpha} L^{\beta-1}}=1 .
$$

Hence, the optimal capital-labour ratio $K_{1} / L_{1}$ is defined as follows:

$$
\frac{K_{1}}{L_{1}}=\frac{\alpha}{\beta},
$$

which means that the investment of funds in production funds and labour will be optimal in the proportion of the elasticity of output on the basis of certain factors if the econometric model based on the PF (10) is adequate.

Let us verify the validity of the obtained formula (13) using a mathematical analysis of the Cobb-Douglas PF in order to determine the optimal capital-labour ratio according to the criterion of "maximum output". We find $L_{1}$ from the equation of interaction $L_{1}=C_{1}-K_{1}$, substitute it into formula (10) and look for its maximum to solve this problem.

$$
Y=A K^{\alpha}\left(C_{1}-K_{1}\right)^{\beta} \rightarrow \max .
$$

We find $\frac{\partial Y}{\partial K}$ - the first partial derivative of the function (14) by Kon the segment [0; C] and define the critical points, in which it is equal to 0 or $\infty$. As a result of elementary transformations, we obtain:

$$
\frac{\partial Y}{\partial K}=A K_{1}^{\alpha-1}\left(C_{1}-K_{1}\right)^{\beta-1}\left[a\left(C_{1}-K_{1}\right)-\beta K_{1}\right] .
$$

It is obvious that $\frac{\partial Y}{\partial K}=0$ when one of the summands of formula (15) is equal to 0. Taking into account neoclassical conditions $A>0, K>0, L>0$ expression (15) is equal to zero for a $\left(C_{1}-K_{1}\right)-\beta K_{1}=0$. It follows that the point

$$
K_{1}=\frac{\alpha}{\alpha+\beta} C_{1}
$$

is critical. From formula (16) and the ratio $L_{1}=C_{1}-K_{1}$ follows

$$
L_{1}=\frac{\beta}{\alpha+\beta} C_{1} \text {. }
$$

We obtain the desired optimal capital-labour ratio $K_{1} / L_{1}$ by dividing the expression (16) into (17), which completely coincides with the formula (13).

We find the maximum of output in terms of optimal capital-labour ratio and the adequacy of the CobbDouglas PF of the researching economic phenomenon by having expressed $K_{1}$ from the formula (13) and substituting it into $(10)$ :

$$
K_{1}=\frac{\alpha}{\beta} L_{1} ; \quad Y_{M A X}=\left(\frac{\alpha}{\beta}\right)^{\alpha} L_{1}^{\alpha+\beta} .
$$

Let us consider the implementation of the principle of equal margin in determining the optimal capital-labour ratio for the CES-function

$$
Y=\grave{A}_{0}\left[\grave{A}_{1} K^{-\check{\delta}}+\left(1-\grave{A}_{1}\right) L^{-\delta}\right]^{-\frac{\gamma}{\delta}},
$$

where $A_{0}$ is the coefficient of the scale $\left(0<A_{0}\right) ; A_{1}-$ coefficient of weight of the production factor $\left(0<A_{1}<1\right)$; $\mathrm{p}$ is the substitution parameter $(-1<\mathrm{p}) ; \gamma$ is the degree of homogeneity $(0<\gamma)$.

PF (19) also applies to neoclassical functions (see Fig. 1) when it is performing restrictions on unknown parameters specified in brackets. Its elasticity of the replacement of the factors $\sigma_{K L}$ is also constant but it may acquire any value.

The first partial derivatives of the CES-functions on $K$ and $L$ are:

$$
\frac{\partial Y}{\partial K}=\frac{A_{1}}{A_{0}{ }^{p}}\left(\frac{Y}{K_{1}}\right)^{1+p} ; \frac{\partial Y}{\partial L}=\frac{1-A_{1}}{A_{0}{ }^{p}}\left(\frac{Y}{L_{1}}\right)^{1+p} .
$$

Then condition (9) for PF (19) is written as follows:

$$
M R S_{L K}=\frac{\partial Y}{\partial K}: \frac{\partial Y}{\partial L}=\frac{A_{1}}{1-A_{1}}\left(\frac{L_{1}}{K_{1}}\right)^{1+p}=1 .
$$

Hence, the optimal capital-labour ratio $K_{1} / L_{1}$ is defined as follows:

$$
\frac{K_{1}}{L_{1}}=\left(\frac{A_{1}}{1-A_{1}}\right)^{\frac{1}{1+p}} \text {. }
$$

Maximum production output in conditions of optimum capital-labour ratio and adequacy of CES-function of the studied economic phenomenon is equal to:

$$
K_{1}=L_{1}\left(\frac{A_{1}}{1-A_{1}}\right)^{\frac{1}{p+1}} ; Y_{M A X}=A_{0} L_{1}^{\left(\gamma+\frac{\gamma}{p}\right)}\left[\left(1-A_{1}\right) C_{1}\right]^{-\frac{\gamma}{p}} \text {. }
$$

The verification of the validity of the obtained formula (22) by using the mathematical analysis of the CESfunction and Allen function on the basis of the criterion 
of "maximum output" is given in works (Yankovyi, 2017; Koval, Slobodianiuk, Yankovyi, 2018).

Let us discuss determining the optimal capital-labour ratio by the principle of equal margin for the linear PF:

$$
Y-A_{2}=A_{3} K+A_{4} L \text {, }
$$

where $A_{2}$ is a free member; $A_{3}, A_{4}$ - parameters of the linear function, expressing the marginal products of production factors "fixed assets" and "labour".

A linear function does not belong to a neoclassical because the conditions $K>0, \mathrm{~L}>0$ are not met for it. However, its substitution of factors is nonzero $\left(\sigma_{L K}=+\infty\right)$, therefore, the isocosts of the PF (24) are straight lines, which are crossing the coordinate axis (Fig. 2).

The first partial derivatives of expression (24) in $K$ and $L$ are $A_{3}, A_{4}$. Therefore, the optimal capital-labour ratio does not depend on the specific values of $K, L$, however, according to condition (9), the equality $A_{3}=A_{4}$ must be satisfied. This means that the set of points of isocost $A B$ in Fig. 2, which corresponds to the aggregate costs $C_{1}=$ $K_{1}+L_{1}$ and coincides with the isoquant

$$
Y_{2}-A_{2}=A_{3} C_{1}
$$

provides the optimal capital-labour ratio.

The maximum of products in value terms is $Y_{\text {MAX }}=A_{3} C_{1}+A_{2}$.

Let us consider the implementation of the principle of equal margin in determining the optimal capital-labour ratio within Leontief function:

$$
Y=\min \left(\frac{K}{c_{1}} ; \frac{L}{c_{2}}\right)
$$

where $c_{1}$ - the capacity of the production unit $\left(0<c_{1}\right)$; $c_{2}$ - the complexity of the production unit $\left(0<c_{2}\right)$.

PF (26) also does not belong to the neoclassical because it is not twice differentiated. Moreover, it is a function with zero substitution of factors $\left(\sigma_{L K}=0\right)$, and its isoquants are perpendicular beams (Fig. 3).

Consequently, the principle of equal margin of determining the optimal capital-labour ratio within the Leontief PF does not work since for it the marginal products of the factors $K, L$ are zero and the marginal rate of substitution is the uncertainty of type $0 / 0$.

Meanwhile, by performing a mathematical analysis of Leontief PF on the criterion of "maximum output" it is easy to show that its optimal capital stock is on the beam OE (Fig. 3):

$$
\frac{K_{1}}{L_{1}}=\frac{c_{1}}{c_{2}} \text {. }
$$

The maximum output at given costs $C_{1}$ at this point is $Y_{M A X}=C_{1} /\left(c_{1}+c_{2}\right)$.

$$
\frac{K}{L}=\frac{c_{1}}{c_{2}}
$$

\section{Practical application of the obtained theoretical results}

Approval of the obtained theoretical results can be carried out according to the data of machine building of Ukraine for 2007-2015 (Table 1). As a productive variable, $\mathrm{Y}$ was considered the realized production of the industry, and as production factors: $\mathrm{K}$ - the residual value (without depreciation) of the main productive assets, $\mathrm{L}$ - labour costs, $\mathrm{t}$ is the factor of time.

In modelling the indices of the engineering industry, a dynamized linear function (24) was used, but its accuracy $\left(R^{2}=0.480\right)$ was not the highest. The parameters of the dynamized CES function (19) found at the third iteration were in general contradictory to the economic content. It turned out that the dynamized Cobb-Douglas production function (the

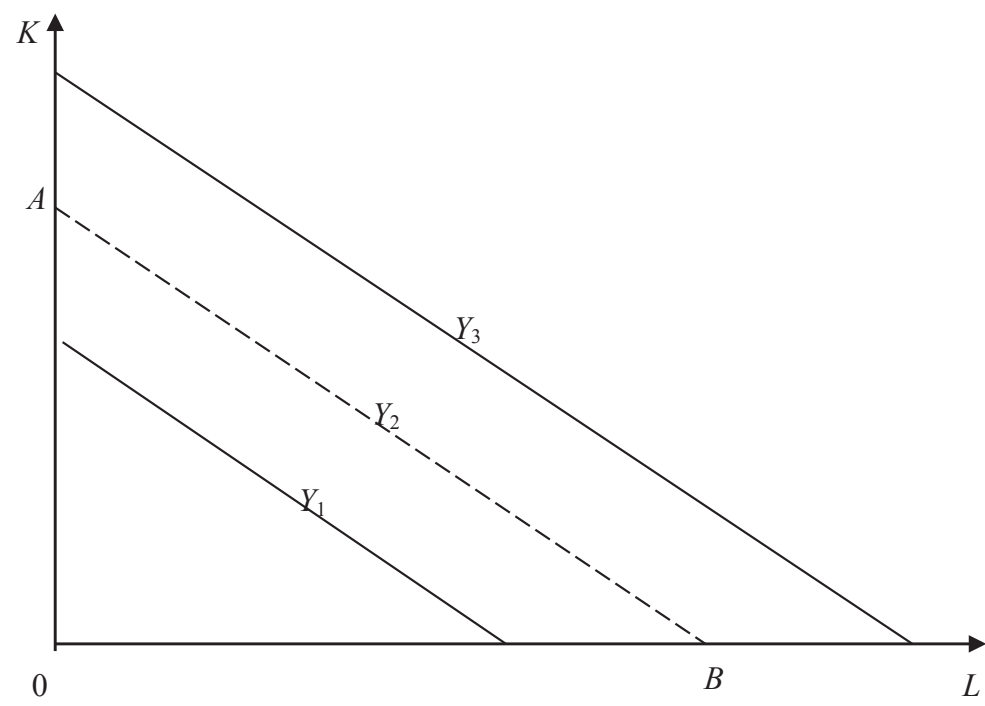

Figure 2. Determination of the set of optimal points on the isoquant and isocost map for a linear two-factor PF with infinite substitution $\left(Y_{3}>Y_{2}>Y_{1}\right)$

Source: built by the authors 


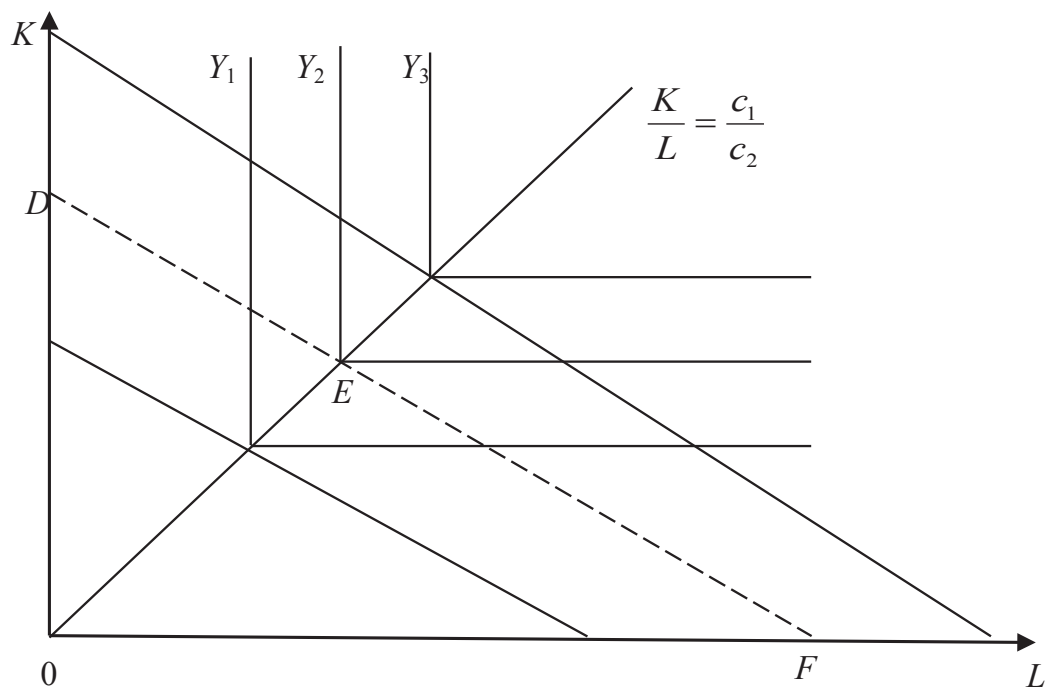

Figure 3. Determination of the optimal point on the isoquant and isocost map for a two-factor Leontief PF with a zero substitution $\left(Y_{3}>Y_{2}>Y_{1}\right)$.

Source: built by the authors

Table 1

Initial data for modelling the dependence of the sales of machine-building products of Ukraine on the main production factors

\begin{tabular}{|c|c|c|c|c|c|}
\hline Years & $Y(m \ln$. UAH. $)$ & $K,(m \ln . \mathrm{UAH})$ & $L,(\mathrm{mln} . \mathrm{UAH}$ & $t$ & $K / L(\mathrm{UAH} / \mathrm{UAH})$. \\
\hline 2007 & 98339,9 & 27854 & 11834,3 & 1 & 2,354 \\
\hline 2008 & 121780,4 & 33489 & 14748,5 & 2 & 2,271 \\
\hline 2009 & 85833,0 & 33475 & 11874,1 & 3 & 2,819 \\
\hline 2010 & 97056,9 & 36075 & 15689,2 & 4 & 2,299 \\
\hline 2011 & 130847,9 & 40417 & 15196,1 & 5 & 2,660 \\
\hline 2012 & 140539,3 & 43642 & 17025,2 & 6 & 2,563 \\
\hline 2013 & 113926,6 & 47268 & 17242,9 & 7 & 2,741 \\
\hline 2014 & 101924,7 & 45894 & 16092,9 & 8 & 2,852 \\
\hline 2015 & 115261,7 & 84052 & 17484,1 & 9 & 4,807 \\
\hline
\end{tabular}

Source: compiled by the authors by State Statistics Service of Ukraine

so-called Cobb-Douglas-Tinbergen function) provides the most accurate results of approximating the initial information $\left(R^{2}=0.524\right)$.

Thus, by logging the data of Table 1 and using the standard Excel regression program, the following equation was obtained:

$$
Y=0,4978 e^{-0,046 t} K^{0,1115} L^{1,1802} \text {. }
$$

Model (28) relatively accurately describes the dynamics of the industry's products sold during the period under study: the determination coefficient indicates that more than $52 \%$ of the variation of $\mathrm{Y}$ is due to three factors of the Cobb-Douglas-Tinbergen function. The average absolute error of the equation is 0.138 million UAH.

The elasticity coefficients $\alpha$ and $\beta$ of the model (28) show that in 2007-2015, the increase in capital expenditure on basic production assets by $1 \%$ entailed an increase in the volume of sales for the year by an average of only $0.1 \%$, while an increase in labour costs by $1 \%$ caused an increase in sales by almost $1.2 \%$. This indicates a certain relative redundancy of the resource $K$ in comparison with the resource $L$. The negative growth rate of the neutral scientific and technical progress indicates that in the engineering industry of Ukraine in the period under review, the realization decreased on average by $4.6 \%$ during the year under the influence of all factors except changes in the costs of fixed assets and labour.

Based on the data of Table 1, there was calculated the marginal rate of replacement of $M R S_{L K}$ in the industry for each year of the period under study (Table 2), taking into account the fact that for the Cobb-Douglas-Tinbergen production function it is determined by the formula

$$
M R S_{L K}=\frac{\beta}{\alpha} \times \frac{K}{L} .
$$

As it was shown earlier, under the conditions of optimal stock-endowment, the marginal rate of substitution of $M R S_{L K}$ for any substitutional production function is equal to one. Let the actual marginal rate of substitution of the production function of machine building differ from unity, and then two cases are possible: 1) $M R S_{L K}>1$;2) $M R S_{L K}<1$. 
Table 2

The marginal rate of substitution in mechanical engineering in Ukraine

\begin{tabular}{|l|l|l|}
\hline Years & $K / L$ & $M R S_{L K}$ \\
\hline 2007 & 2,354 & 24,907 \\
\hline 2008 & 2,271 & 24,029 \\
\hline 2009 & 2,819 & 29,828 \\
\hline 2010 & 2,299 & 24,325 \\
\hline 2011 & 2,660 & 28,145 \\
\hline 2012 & 2,563 & 27,119 \\
\hline 2013 & 2,741 & 29,002 \\
\hline 2014 & 2,852 & 30,177 \\
\hline 2015 & 4,807 & 50,862 \\
\hline
\end{tabular}

Source: compiled by the authors

On the basis of the parameters of the model (28), we calculate the index of the average optimal capital-labour ratio in the industry for 2007-2015 by the formula (13):

$$
\frac{K_{1}}{L_{1}}=\frac{\alpha}{\beta}=\frac{0,1115}{1,1802}=0,0945 \text {. }
$$

It is clear that these calculations have an approximate, evaluation character. They will acquire greater validity in the case of increasing the accuracy of the reference model (28), that is, as the condition $R_{2} \rightarrow 1$ is satisfied.

\section{Conclusion}

The development of ideas of the principle of equal margin from the theory of microeconomics and examples of determining the optimal capital-labour ratio for the PF, generalized by the CES-function, shows the simplicity and effectiveness of the proposed approach to the analysis of extreme interrelations between output and aggregate production factors. An exception is a zerosubstitution PF, for example, the Leontief function.

The use of the proposed procedure for determining the optimal capital-labour ratio is performed using the example of the Cobb-Douglas-Tinbergen production function, the dynamized CES function, and the linear function. For them, formulas are given for the optimal fund-raising ratio with an indication of the extreme values of output and total capital expenditure on basic production assets and labour remuneration. The obtained theoretical results are tested on the data of machine building of Ukraine for 2007-2015. The built econometric model allowed coming to a conclusion about the non-optimal funds-in-use in terms of sales volumes of industrial products. It turns out that during the analysed period of time, the basic production assets were relatively abundant in comparison with the wages of workers in machine building. Obviously, in the Ukrainian engineering industry, it is necessary to reduce excess technological equipment or to increase pay by attracting additional workers, enhancing their material incentives. This will allow reversing the negative trend in the dynamics of the industry's assets-endowment, lead to a certain reduction in it and a gradual approach to the optimal value.

\section{References:}

Pyndaik R. \& Rabynfeld D. (2002). Microeconomics. SPb.: Piter. (in Russian)

Galperin V.M. \& Ignatev S.M. (2004). Microeconomics. SPb. (in Russian)

Perloff J.M. (2014). Microeconomics. Chapter 7: Costs. Retrieved from: http://wps.aw.com

Debertin D.L. (2012). Agricultural Production Economics. Amazon Createspace.

Borovskoj D.N. (2008). Production functions and the problem of choosing the economic-mathematical model of the active element. Radioelektronni i kompjuterni sistemi, 1(28), 172-177. (in Russian)

Kazakova M.V. (2013). Analysis of the properties of production functions used in the decomposition of economic growth. Retrieved from: ftp://ftp.repec.org/opt/ReDIF/RePEc/rnp/wpaper/31.pdf (in Russian)

Podladchikov V.N. (2012). Microeconomics. Production functions. Retrieved from: http://i.kpi.ua/ podladchikov/-menu=micro-firm-2-.htm (in Russian)

Cherevko J.V. (2007). Optimal capital stock and initial capital. Visnyk socialjno-ekonomichnykh doslidzhenj, 26, 359-365 (in Ukrainian)

Shumsjka, S. S. (2007). Production function in economic analysis: theory and practice of use. Ekonomika proghnozuvannja, 2, 138-153 (in Ukrainian)

Yankovyi V.A. (2017). The application of the CES function and associated production functions in economic research. Naukovyj visnyk Mizhnarodnogho ghumanitarnogho universytetu, 23 (2), 156-159. (in Russian)

Koval V., Slobodianiuk O., Yankovyi V. (2018). Production forecasting and evaluation of investments using Allen two-factor production function. Baltic Journal of Economic Studies Vol. 4, No. 1: $219-226$. DOI: https://doi.org/10.30525/2256-0742/2018-4-1-219-226

State Statistics Service of Ukraine (2018). Retrieved from: http://www.ukrstat.gov.ua/ 